\title{
Das cinzas da estação Belém
}

\section{Denise de Alcantara}

\section{(2) OpenEdition}

Journals

Edição electrónica

URL: http://journals.openedition.org/espacoeconomia/14872

DOI: 10.4000/espacoeconomia.14872

ISSN: 2317-7837

\section{Editora}

Núcleo de Pesquisa Espaço \& Economia

Refêrencia eletrónica

Denise de Alcantara, «Das cinzas da estação Belém », Espaço e Economia [Online], 19 | 2020, posto online no dia 25 agosto 2020, consultado o 15 setembro 2020. URL : http://journals.openedition.org/ espacoeconomia/14872

Este documento foi criado de forma automática no dia 15 setembro 2020.

(C) NUPEE 


\title{
Das cinzas da estação Belém
}

\author{
Denise de Alcantara
}

\section{NOTA DO AUTOR}

Este texto, que nasceu como um suspiro de pesar, foi tornado público originalmente no Portal da UFRRJ no dia 27/07/2020, disponível em http://portal.ufrrj.br/das-cinzas-daestacao-de-belem.

1 O fogo é feroz, consome com avidez. O fogo destrói, florestas, vidas, bens. O fogo sufoca a história, mais uma vez.

2 A Estação de Trem, o símbolo, talvez único e sem dúvida o mais significante, da evolução urbana de Japeri, hoje foi arrasado pelas chamas. Em poucas horas, o patrimônio histórico ferroviário se desintegrou.

3 Tombado pelo IPHAN e havia anos abandonado pela Supervia, desde 2018 o edifício estava sendo recuperado pela prefeitura após disputa judicial, com as obras em etapa de conclusão. 
Figura 1 : Estação Belém em Japeri

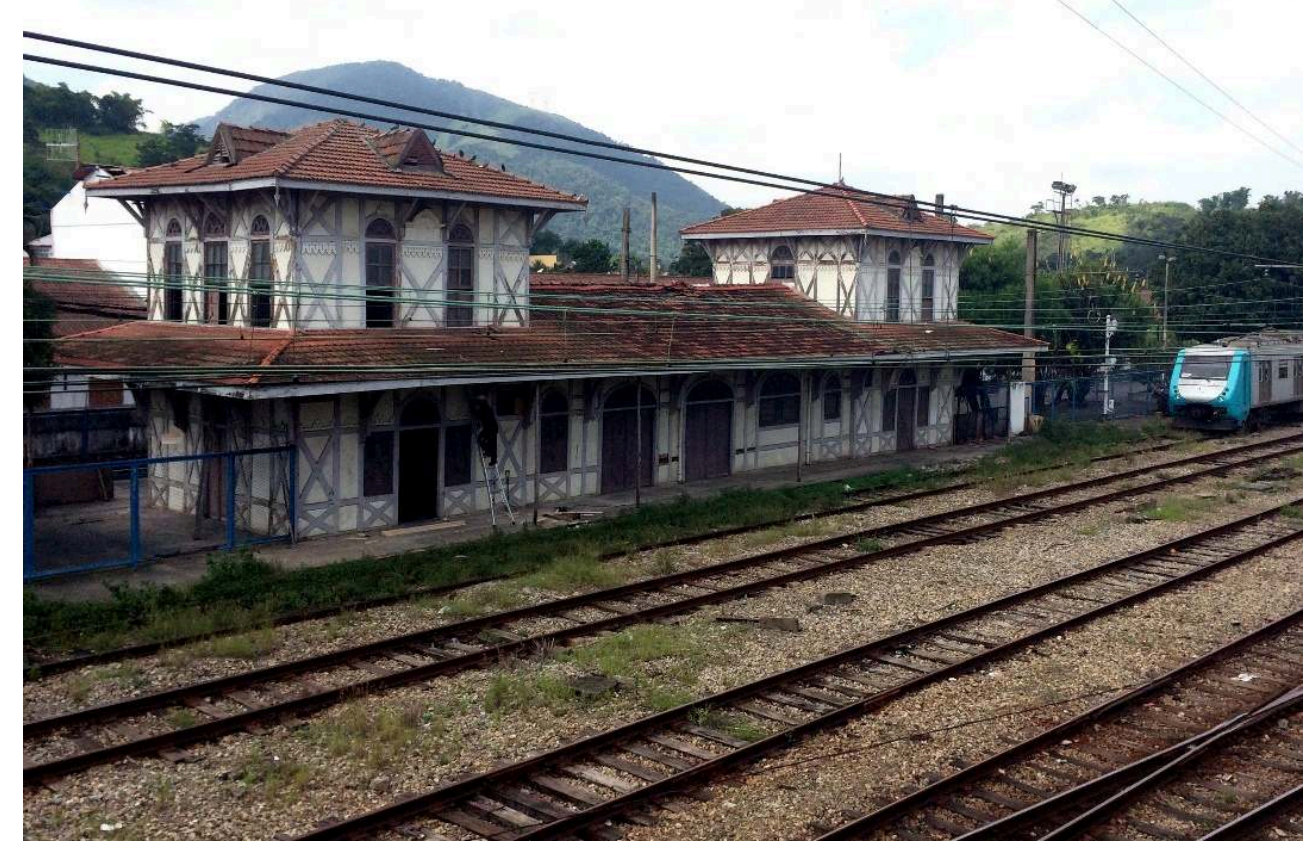

Fonte : Foto da autora, março de 2018.

4 A que se deve o fogo? Seria criminoso? Um balão caído, uma fagulha, uma guimba lançada a esmo? Uma intenção velada pela madrugada escura e fria de um domingo de inverno seco?

5 Nossa Senhora Virgem de Fátima por anos a seu lado esteve, mas presa e enjaulada, protegida de vandalismos e maldades alheias, não pode proteger o edifício do destino fatal. 
Figura 2 : Nossa Senhora Virgem de Fátima.

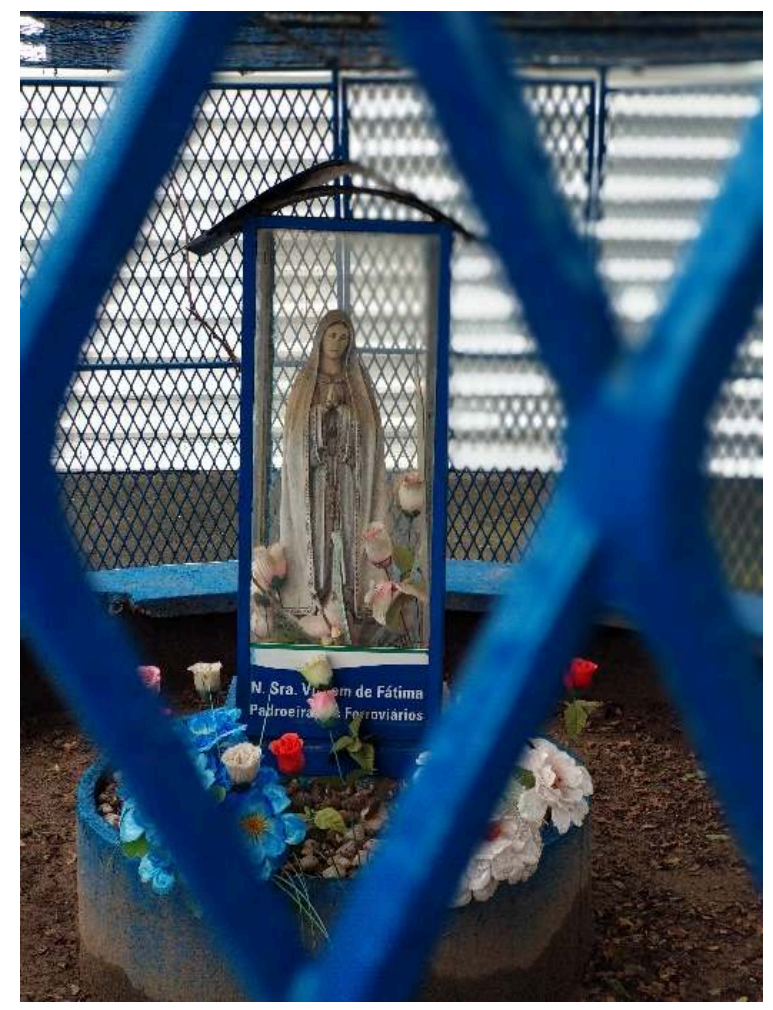

Fonte : Foto de Fernanda Marchon, dezembro de 2018.

6 O fogo é simbólico. Do descaso, da negligência, do desapego com a história, com a memória, com o bem público, a cultura. As técnicas da restauração falharam quando não previram nem evitaram o potencial das chamas. 0 edifício histórico, que guardava a dignidade de uma era, sucumbiu sem socorro, sem compaixão, sem salvação. 0 investimento na recuperação, tampouco garantiu sua permanência.

7 Único e imponente edifício representante de uma era erigido em 1858, seu primeiro nome foi Estação Belém. A técnica de enxaimel inspirava-se nas construções do norte europeu com estrutura em pilares e caibros de madeira, emoldurando a vedação em tijolo cerâmico maciço. $\mathrm{O}$ telhado recoberto por telhas francesas originais se dividia em quatro águas nos três elementos que configuravam a bela estação. Do corpo único e longo no primeiro piso, sobressaiam, no segundo piso, dois corpos laterais distintos, também recobertos em quatro águas encimadas por mansardas. As fachadas evidenciavam em desenhos geométricos a estrutura em madeira, as mãos francesas e os apliques. Sua relevância arquitetônica e histórica é inquestionável. 
Figura 3 : Casarão da Estação Belém.

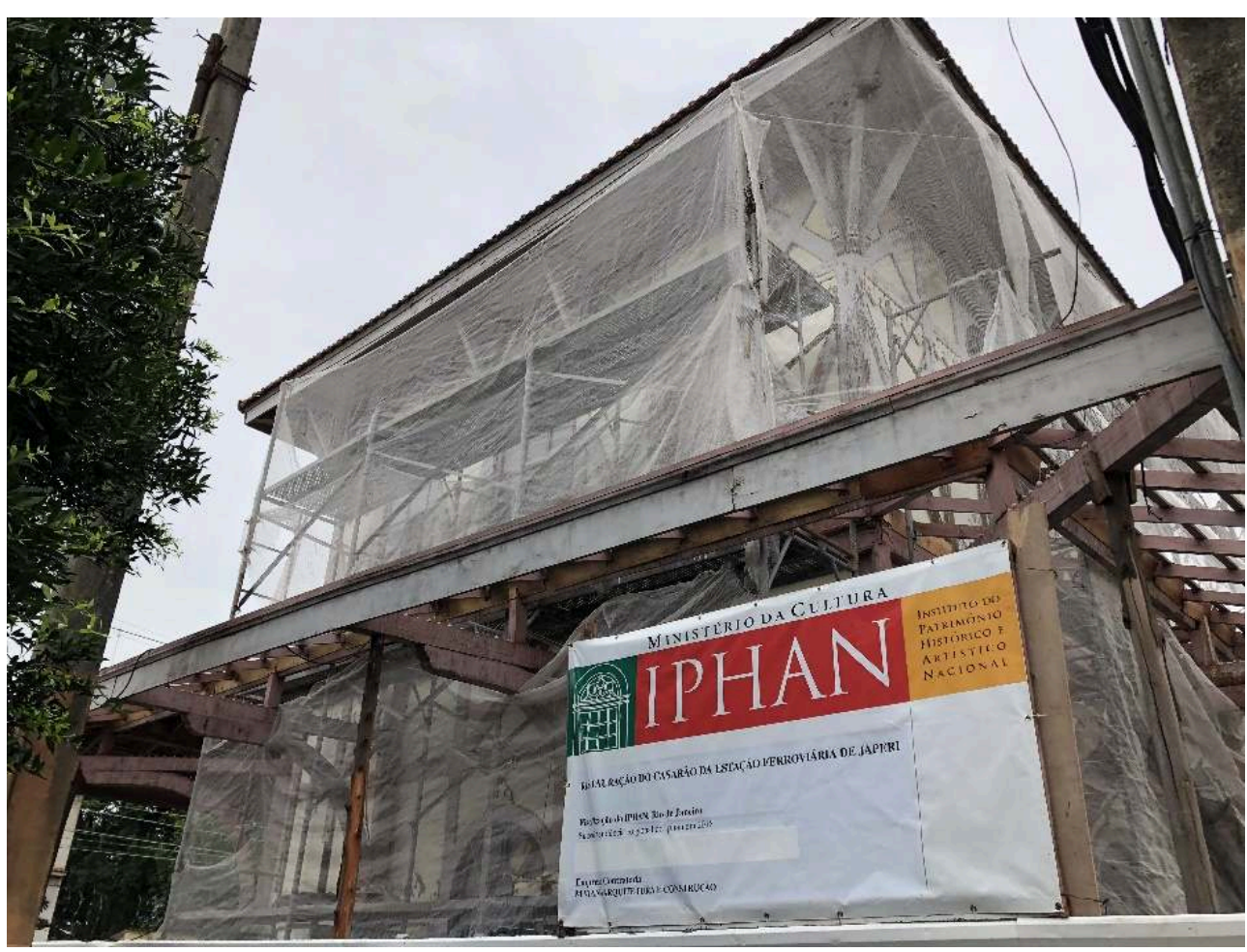

Fonte : Foto da Autora, dezembro de 2018.

Para quem a conhecia, o habitante, os filhos da cidade, e mesmo para nós forasteiros que enxergam as potências do lugar, o incêndio da Estação Belém tem para Japeri um peso relativo ao que a perda da sede do Museu Histórico Nacional representa para o Rio de Janeiro.

9 A imagética de Japeri construída pela mídia, alimentada pelas tristes notícias cotidianas que exploram a pobreza, a violência e o crime no lugar, ganha mais essa triste manchete. A Estação Belém, quase pronta para recuperar seu uso e esplendor, transforma-se em cinzas.

10 É mais um retrato de um país em chamas, é mais um exemplo do descaso, da negligência, do descuido com o que é público, com o que deveria ser resguardado e protegido: a cultura, a história, o patrimônio, o ambiente, a saúde, a educação, enfim, o bem-estar da população.

11 Talvez das tristes cinzas ainda possam brotar sementes de esperança. A esperança que habita em cada coração japeriense, em suas memórias afetivas, em sua história de lutas e de movimentos sociais, na coesão social que segue como fio condutor de superação de tantas adversidades e privações.

12 Que essa perda material transformada em cinzas não seja em vão. Que faça renascer em cada ser o sentido de pertencer e defender o que é de todos por meio da ação coletiva, da participação e da inclusão.

13 Em 19/07/2020. 


\section{BIBLIOGRAFIA}

ESTAÇÕES FERROVIÁRIAS DO BRASIL. Estação de Japeri. Página da Internet. Disponível em http://www.estacoesferroviarias.com.br/efcb_rj_linha_centro/japeri.htm Acesso: 22/5/2019.

MEDEIROS, L. Lugares de Memória dos Trabalhadores \#23: Pedra Lisa, Japeri (RJ). 2020. Disponível em https://lehmt.org/2020/03/05/lugares-de-memoria-dos-trabalhadores-23-pedra-lisa-japerirj-leonilde-servolo-de-medeiros/

REIS, E.; ALCANTARA, D. Patrimônio, Identidade e Territorialidade: o SIG na proposta de uma nova imagética para Japeri. In Anais do 3o. Simpósio Científico ICOMOS/BRASIL. Belo Horizonte: UFMG, 2019.

\section{AUTOR}

\section{DENISE DE ALCANTARA}

Professora do Departamento de Arquitetura e Urbanismo e do Programa de Pós-Graduação em Desenvolvimento Territorial e Políticas Públicas e Pesquisadora Líder do Grupo GEDUR, da Universidade Federal Rural do Rio de Janeiro, Mestre e Doutora pelo PROARQ-UFRJ e Bolsista de Produtividade JCNE-FAPERJ com a pesquisa Territórios e Paisagens Perimetropolitanos: conflitos e desigualdades sócio-espaciais e cenários prospectivos no Rio de Janeiro na perspectiva da Nova Agenda Urbana 2030. A autora coordena e desenvolve junto ao Grupo GEDUR-UFRRJ pesquisa abrangente sobre os conflitos e desigualdades sócio-espaciais e questões urbanas sob a perspectiva da Agenda 2030 no Oeste Metropolitano (financiado com Bolsa JCNE FAPERJ E-26/202.706/2018). E-mail: denisedealcantara@gmail.com. 